\title{
Contrast enhanced magnetic resonance imaging of the foot in horses using intravenous versus regional intraarterial injection of gadolinium
}

\author{
Donatella De Zani ${ }^{1, *}$, Vanessa Rabbogliatti ${ }^{1}$, Giuliano Ravasio ${ }^{1}$, Cinzia Pettinato ${ }^{2}$, Mauro Di Giancamillo ${ }^{1}$ and \\ Davide Danilo Zani ${ }^{1}$ \\ ${ }^{1}$ Dipartimento di Medicina Veterinaria, Centro Clinico Veterinario e Zootecnico Sperimentale, Università degli \\ Studi di Milano, Italy \\ ${ }^{2}$ Department of Medical Physics, Policlinico S.Orsola-Malpighi, Bologna, Italy
}

\begin{abstract}
The use of contrast enhanced magnetic resonance imaging (MRI) for the detection of orthopedic pathologies in equine patients is poorly described. In few studies, enhanced MRI allowed to differentiate active lesions from chronic ones and to classify ambiguous lesions. The aim of this clinical prospective pilot study is to describe and compare the MRI lesions observed in horses with lameness localized to the foot using a single intravenous bolus dose of gadolinium contrast versus regional intraarterial bolus of contrast agent. Ten horses that underwent contrast enhanced MRI were included in the study. Gadolinium was injected intravenously in 3 patients and in 7 horses contrast agent was administered by intraarterial regional delivery. Regions of interest (ROI) were collected from both pre- and postcontrast images and ratios between pre- and post-contrast ROIs were calculated. No adverse reactions were noted after contrast agent injection. Injured structures that revealed greater increase in signal in post-contrast images were the deep digital flexor tendon (DDFT), the navicular spongiosa and the peritendinous tissues. Regional intraarterial administration of gadolinium provided higher ratio of contrast enhancement. Enhanced MRI using both intravenous or intraarterial injection of gadolinium, increased the diagnostic capability of MRI in horses with foot lesions. Nevertheless, regional intraarterial administration of gadolinium was considered the best choice due to the higher signal and lower volumes of contrast agent required.
\end{abstract}

Keywords: Contrast Agent, Equine, Lameness, MRI, Orthopedic.

\section{Introduction}

Magnetic resonance imaging (MRI) is widely used in the diagnosis of orthopaedic disease in horses. As a consequence of the high sensitivity of MRI in detection of changes within soft tissues, understanding which lesions are involved in the current clinical process may be difficult (Judy et al., 2010; Severaid and Judy, 2012). Some signal alterations have been described on both sound and lame horses (Dyson and Murray, 2007; Murray et al., 2007; Holowinsky et al., 2010). Holowinsky et al. (2010) observed that resolution of tendons and ligaments lesions on STIR images was related to an improvement of the lameness. Otherwise, when bone marrow lesions were present, there was no correlation between clinical signs and resolution of lesions in STIR sequences (Holowinsky et al., 2010). Furthermore, some subtle lesions can be overlooked or underestimated, especially using low field system (Dyson et al., 2010; Judy et al., 2010).

To avoid underestimation, overlooking and to evaluate the dynamic status of an injury, in humans contrast enhanced MRI has been performed since the early 1990s (Beltran et al., 1991; Sofka and Potter, 2001; Schmid et al., 2002; Hodgson et al., 2012; Gärdin et al.,
2013; Ntoulia et al., 2013; Tavares et al., 2014). Eshed et al. (2015) demonstrated that un-enhanced MRI using STIR sequences was only moderately reliable for synovitis assessment when contrast enhanced MRI was considered the gold standard.

There are only few reports describing the use of contrast enhanced MRI (Ferrell et al., 2002; Judy et al., 2010; Severaid and Judy, 2012; De Zani et al., 2013; Nelson et al., 2017; Aarsvold et al., 2018) in horses while the use of contrast medium is well reported in computed tomography (CT) (Puchalski et al., 2007, 2009; Puchalski, 2012; Vallance et al., 2012; Van Hamel et al., 2014; Carmalt and Montgomery, 2015; Nelson et al., 2017).

The high capability of enhanced CT and MRI in soft tissue lesion detection has been proved but the administration of an appropriate systemic dose of intravenous contrast agent is not practical due to the large volume required. To significantly reduce the contrast agent dose and injection time, regional intraarterial administration contrast agent has been used in CT studies of the equine distal limb and head, and a small but statistically significant increase in attenuation of soft tissue was observed (Puchalski et al., 2007; 
Carmalt and Montgmomery, 2015). Aarsvold et al. (2018), described the use of enhanced MRI following regional limb perfusion in horses, after contrast medium administration via a palmar/plantar digital vein. Authors proved that contrast enhanced MRI increased the detection of lesions, especially of the collateral sesamoidean and impar ligament.

To the authors knowledge, intraarterial injection of contrast agent for MRI in the equine patient has never been described, while in human medicine it was used in pediatric patients or in patients with sensitivity to iodinated-contrast agent to avoid problems related to iodinate toxicity (Arat et al., 2000; Spinosa et al., 2002; Zeller et al., 2002; Burry et al., 2004).

The aim of this study is to describe the effectiveness of enhanced MRI in equine patients with lameness localized to the foot region using a single intravenous bolus dose of gadolinium contrast versus regional intraarterial bolus of contrast agent and comparing the contrast enhancement obtained using the systemic injection versus the loco-regional administration of contrast agent.

\section{Materials and Methods \\ Selection and Description of Subjects}

The study was a clinical prospective pilot study. Ten horses with unilateral lameness localized to the foot region were included in the study, which was conducted between January 2014 and December 2014. Owners were consulted prior inclusion in the study and written and verbal consent was obtained. A complete physical examination, complete blood count and survey radiographs of both front feet were obtained.

Ten horses were included in the study. Horses were of different breed, the mean age was 10.5 years (range between 1 and 16 years); there were 2 stallions, 6 geldings and 2 mares. Six right forelimbs, 3 left forelimbs and one right hind limb were evaluated using contrast enhanced MRI.

Three horses were included in Group 1 and received the contrast agent injection into the right jugular vein. Seven horses were included in Group 2 and the contrast agent was administered in the radial artery (6 horses) or in the dorsal metatarsal artery (1 horse).

Horses were premedicated with intravenous xylazine $(1,1 \mathrm{mg} / \mathrm{kg}$ ) (Nerfasin, A.T.I. s.r.l., Ozzano Emilia, Italy), and acepromazine $(0.03 \mathrm{mg} / \mathrm{kg})$ (Prequillan, Fatro S.p.A., Ozzano Emilia, Italy), and anesthesia was induced using a combination of ketamine $(2.2 \mathrm{mg} / \mathrm{kg})$ (Ketavet 100, Intervet Productions, Peschiera Borromeo, Italy), and diazepam $(0.05 \mathrm{mg} / \mathrm{kg})$ (Valium, Roche, Basel, Switzerland).

Anesthesia was maintained with isoflorane (IsofluraneVet, Merial Italia S.p.A., Milano, Italy) in oxygen. The horses were positioned on a custom made MRI compatible table on left lateral recumbency. Magnetic resonance images were acquired using a low-field magnet (0.18 T) (MR-Vet; Esaote, Genova, Italy) and a knee-receiving coil. The acquisition protocol included sagittal and transverse three-dimensional T1-weighted gradient echo sequences (T3DT1), sagittal and dorsal short $\tau$ inversion recovery sequences (STIR) and transverse dual echo sequences (ME). Images were obtained using a $1 \mathrm{~mm}$ slice thickness for the T3DT1 sequences and a $4 \mathrm{~mm}$ slice thickness with a $0.4 \mathrm{~mm}$ gap for all other sequences. After contrast agent, gadodiamide (Omniscan, GE Healthcare S.r.1., Milano, Italy) injection, T3DT1 sequences in three different orthogonal planes were acquired. Contrast agent was administered using two different protocols: systemic intravenous injection (Group 1) and intraarterial regional delivery (Group 2). Each horse was assigned randomly to Group 1 or Group 2. Systemic intravenous injection was performed using a $14 \mathrm{G}$ catheter in the right jugular vein and $0.1 \mathrm{ml} / \mathrm{kg}$ of contrast agent was injected. The intraarterial regional injection was performed using a $20 \mathrm{G}$ catheter placed in the radial artery. A tourniquet was placed just distal to the carpal or tarsal joint and $0.02 \mathrm{ml} / \mathrm{kg}$ of contrast agent were administered. Post-contrast sequences were acquired immediately after contrast medium injection.

\section{Ethical considerations}

Animals included in the study underwent to radiographic and magnetic resonance examination for clinical investigation following the good veterinary practice and after obtaining informed client consent.

\section{Data recording and Analysis}

Using a dedicated DICOM software (OsiriX; Pixmeo SARL, Geneve, Switzerland) MD, Regions Of Interest (ROI) pixel intensity of specific area were collected from both pre- and post-contrast images. Measurements were retrospectively assessed by a single observer. The ROIs included four predefined regions and four areas with abnormal findings (Table 1). In order to evaluate the value of contrast enhancement ratios between preand post-contrast ROIs were calculated dividing the difference between the post-contrast ROI value and the pre-contrast ROI value by the pre-contrast ROI value.

\section{Statistics}

A paired t-test was used to determine if the signal intensity of the post-contrast ROI obtained with the two different contrast agent administration protocols was significantly different from the pre-contrast ROI of both the prearranged normal regions of interest and the pathological regions of interest. Significance was set at $\mathrm{p}<0.05$. An unpaired t-test was used to evaluate the statistical significance of contrast enhancement ratio obtained comparing the systemic intravenous injection of contrast agent and regional intraarterial delivery of gadolinium. Significance was set at $\mathrm{p}<0.05$. Intraobserver agreement was determined using all measurements that were assessed by the same observer twice within 4 weeks. 
Table 1. Localization of the points used for the ROI of both normal (Predefined) and abnormal regions.

\begin{tabular}{|c|c|c|c|c|}
\hline Point & \multicolumn{2}{|c|}{ ROI location } & Predefined Region & $\begin{array}{l}\text { Pathological Region } \\
\text { Alterations detected }\end{array}$ \\
\hline 1 & \multicolumn{2}{|c|}{$\begin{array}{l}\text { Medial palmar digital artery and vein, } 1 \mathrm{~cm} \\
\text { proximal to the navicular bone }\end{array}$} & $\begin{array}{l}\text { Normal structure- } \\
\text { Predefined region }\end{array}$ & \\
\hline 2 & \multicolumn{2}{|c|}{ Dorsal aspect of the Coffin Joint } & $\begin{array}{l}\text { Normal structure- } \\
\text { Predefined region }\end{array}$ & \\
\hline 3 & \multicolumn{2}{|c|}{ Deep Digital Flexor Tendon } & $\begin{array}{l}\text { Normal structure- } \\
\text { Predefined region }\end{array}$ & \\
\hline 4 & \multicolumn{2}{|c|}{$\begin{array}{l}\text { Middle third of the dorsal cortex of the intermediate } \\
\text { phalanx }\end{array}$} & $\begin{array}{l}\text { Normal structure- } \\
\text { Predefined region }\end{array}$ & \\
\hline 5 & $\begin{array}{l}\text { Deep Digital Flexor } \\
\text { Tendon }\end{array}$ & $\begin{array}{l}\text { Region proximal to } \\
\text { navicular bone }\end{array}$ & & $\begin{array}{l}\text { Tears, core lesions, dorsal } \\
\text { abrasion, sagittal and } \\
\text { parasagittal split }\end{array}$ \\
\hline 6 & $\begin{array}{l}\text { Deep Digital Flexor } \\
\text { Tendon }\end{array}$ & $\begin{array}{l}\text { Region at level of navicular } \\
\text { bone }\end{array}$ & & $\begin{array}{l}\text { Tears, core lesions, dorsal } \\
\text { abrasion, sagittal and } \\
\text { parasagittal split }\end{array}$ \\
\hline 7 & $\begin{array}{l}\text { Deep Digital Flexor } \\
\text { Tendon }\end{array}$ & $\begin{array}{l}\text { Region proximal to DDFT } \\
\text { insertion }\end{array}$ & & $\begin{array}{l}\text { Tears, core lesions, dorsal } \\
\text { abrasion, sagittal and } \\
\text { parasagittal split }\end{array}$ \\
\hline 8 & $\begin{array}{l}\text { Distal Sesamoidean Ir } \\
\text { Navicular Bone Spon } \\
\text { Navicular Bone Flexo }\end{array}$ & $\begin{array}{l}\text { ar Ligament (DSIL), } \\
\text { sa, Peritendinous tissue, } \\
\text { Cortex }\end{array}$ & & $\begin{array}{l}\text { DSIL desmitis, Bone Marrow } \\
\text { Lesion, Erosion of the Flexor } \\
\text { Cortex, peritendinous } \\
\text { edema/inflammatory reaction }\end{array}$ \\
\hline
\end{tabular}

Intraobsever agreement indices (AI) were calculated and the means were obtained. An AI of 1 indicated perfect agreement, an AI of $\geq 0.9$ indicated excellent agreement. For all the statistical analysis a specific software was used (SAS; SAS Institute Inc., Cary, North Carolina, USA).

\section{Results}

Horses were monitored during the MRI examination and for the following 48 hours. No adverse reaction or side effects were observed during and after the injection procedure and vital parameters were within the normal range. Total duration of anesthesia ranged between 60 and 70 minutes.

The radial and dorsal metatarsal arteries were identified by palpation and the placement of the catheter was easily carried-out in all horses without US guidance.

Ratio values of contrast enhancement in normal and pathological regions after intravenous bolus of contrast agent were summarized in table 2 . Ratio values of contrast enhancement after intraarterial regional injection were summarized in table 3 .

The normal structures of the prearranged regions that showed greatest contrast enhancement after intravenous bolus were the medial palmar digital artery and vein, the dorsal aspect of the coffin joint capsule and the dorsal cortical bone of the middle phalanx. The deep digital flexor tendon was noted to have a significant enhancement only when pathological (Point 5: $\mathrm{p}=0.05$ and Point 6: $\mathrm{p}=0.011$ ).

Pathological areas different from DDFT showed a mild enhancement, in absence of statistical significance $(\mathrm{p}=0.146)$.
After intraarterial regional injection of contrast agent, normal regions that showed a greater enhancement were the same observed after intravenous bolus administration. In the areas of the deep digital flexor tendon (Point 6 and Point 7) and in the navicular bone spongiosa /peritendinous tissues, a high enhancement was noted, reaching statistical significance in both deep digital flexor tendon (Point 5: $\mathrm{p}=0.02$ and Point 6: $\mathrm{p}=0.05)$ and in the navicular spongiosa/peritendineous tissues $(\mathrm{p}=0.04)$.

The means of ratios values achieved from the two methods of contrast agent administration were compared and the difference of the contrast enhancement obtained from the techniques was noted to be of statistical significance $(\mathrm{p}=0.01)$ (Fig. 1).

Alterations of the DDFT were the most frequent: four lesions were observed in the region proximal to navicular bone, 2 at level of the navicular bone and 6 in the region proximal to DDFT insertion. In 8 horses a distal impar sesamoidean ligament (DSIL) desmopathy was detected and adhesions between DSIL and DDFT were recognized. In two of 8 horses DSIL injuries were observed only on post-contrast images. No involvement of the peritendinous tissues was noted on pre-contrast T1W and on STIR sequences while in post-contrast images it was observed in 3 cases. Enhanced MRI highlighted the presence of presumed scar tissue in 4 horses. On STIR sequences, eight of the twelve lesions involving the DDFT were visible; in two cases, adhesion between DDFT and DSIL were poorly recognizable on fat suppressed images while in 8 horses no alteration of DSIL was detected. 
Table 2. Results of the ratio values obtained after intravenous injection of gadolinium.

\begin{tabular}{ccccccccccc}
\hline \multirow{2}{*}{ Case } & \multicolumn{9}{c}{ Group 1: Ratio values after intravenous bolus of contrast medium } & \multirow{2}{*}{$\begin{array}{c}\text { Dose of contrast } \\
\text { agent }(0.1 \mathrm{ml} / \mathrm{kg})\end{array}$} \\
\cline { 2 - 8 } & Point 1 & Point 2 & Point 3 & Point 4 & Point 5 & Point 6 & Point 7 & Point 8 \\
\hline 1 & 0.649 & 0.552 & 0.012 & 1.442 & 0.575 & 0.680 & 0.187 & 0.578 & $30 \mathrm{ml}$ \\
2 & 0.256 & 0.413 & -0.337 & 0 & 0.235 & 0.198 & 0.261 & 0.194 & $60 \mathrm{ml}$ \\
3 & 0.752 & 0.830 & 0.220 & 0 & 0.857 & 0.464 & 0.159 & 0.694 & $50 \mathrm{ml}$ \\
Mean & 0.552 & 0.598 & -0.035 & 0.481 & 0.556 & 0.447 & 0.202 & 0.489 & \\
$(\mathrm{SD})$ & $(0.26)$ & $(0.21)$ & $(0.28)$ & $(0.83)$ & $(0.31)$ & $(0.24)$ & $(0.05)$ & $(0.26)$ & \\
$p<0.05$ & $t=3.7$ & $t=3.08$ & $t=1.54$ & $t=1.64$ & $t=4.09$ & $t=9.32$ & $t=3.55$ & $t=2.32$ & \\
& $p=0.066$ & $p=0.091$ & $p=0.26$ & $p=0.24$ & $p=0.055$ & $p=0.011$ & $p=0.071$ & $p=0.146$ \\
\hline
\end{tabular}

Table 3. Results of the ratio values obtained after intraarterial injection of gadolinium.

\begin{tabular}{|c|c|c|c|c|c|c|c|c|c|}
\hline \multirow{2}{*}{ Case } & \multicolumn{8}{|c|}{ Group 2: Ratio values after intra-arterial regional injection of contrast medium } & \multirow{2}{*}{$\begin{array}{c}\text { Dose of contrast } \\
\text { agent }(0.02 \mathrm{ml} / \mathrm{kg})\end{array}$} \\
\hline & Point 1 & Point 2 & Point 3 & Point 4 & Point 5 & Point 6 & Point 7 & Point 8 & \\
\hline 1 & 0.718 & 0.089 & 0.384 & 0 & 0.123 & 0.511 & 0.172 & 0.370 & $14 \mathrm{ml}$ \\
\hline 2 & 0.171 & 1.442 & 0.287 & 4.38 & 0.622 & 1.384 & 2.257 & 1.811 & $12 \mathrm{ml}$ \\
\hline 3 & 2.998 & 2.432 & 0.432 & 1.288 & 0.616 & 0.736 & 0.793 & 0.370 & $10 \mathrm{ml}$ \\
\hline 4 & 0.376 & 2.09 & 0.320 & 0.665 & 0.490 & 0.246 & 0.235 & 0.645 & $8 \mathrm{ml}$ \\
\hline 5 & 0.377 & 1.621 & 0.228 & 0 & 0.116 & 0.8 & 1.343 & 0.460 & $10 \mathrm{ml}$ \\
\hline 6 & 0.879 & 0.218 & 0.070 & 0 & 1.29 & 0.623 & 0.412 & 0.394 & $11 \mathrm{ml}$ \\
\hline 7 & 0.663 & 2.364 & 0.392 & 0 & 0.126 & 1.605 & 0.539 & 0.795 & $9 \mathrm{ml}$ \\
\hline $\begin{array}{c}\text { Mean } \\
\text { (SD) }\end{array}$ & $\begin{array}{l}0.883 \\
(0.96)\end{array}$ & $\begin{array}{l}1.465 \\
(0.97)\end{array}$ & $\begin{array}{l}0.302 \\
(0.12)\end{array}$ & $\begin{array}{l}0.905 \\
(1.61)\end{array}$ & $\begin{array}{l}0.483 \\
(0.42)\end{array}$ & $\begin{array}{l}0.844 \\
(0.48)\end{array}$ & $\begin{array}{l}0.822 \\
(0.75)\end{array}$ & $\begin{array}{l}0.692 \\
(0.52)\end{array}$ & \\
\hline$p<0.05$ & $\begin{array}{c}t=2.5 \\
p=0.0465\end{array}$ & $\begin{array}{c}t=3.6 \\
p=0.0114\end{array}$ & $\begin{array}{c}t=5.39 \\
p=0.0017\end{array}$ & $\begin{array}{c}t=1.93 \\
p=0.102\end{array}$ & $\begin{array}{c}t=2.96 \\
p=0.0253\end{array}$ & $\begin{array}{c}t=2.442 \\
p=0.0503\end{array}$ & $\begin{array}{c}t=1.79 \\
p=0.112\end{array}$ & $\begin{array}{c}t=2.50 \\
p=0.0465\end{array}$ & \\
\hline
\end{tabular}

In one case, an erosion of the flexor cortex of the navicular bone was observed in both pre-contrast $\mathrm{T} 1 \mathrm{~W}$ and STIR sequences, showing an intense enhancement after contrast agent injection.

\section{Discussion}

In this pilot study we described the effectiveness of enhanced MRI in equine patients with lameness localized to the foot using a single intravenous bolus dose of gadolinium contrast versus regional intraarterial bolus of contrast agent and comparing the contrast enhancement obtained using the systemic injection versus the loco-regional administration of contrast agent. In all non-pathological predefined regions the high enhancement was observed in the medial palmar digital artery and vein, the dorsal aspect of the coffin joint capsule and the dorsal cortical bone of the middle phalanx but statistical significance was reached only after intraarterial regional contrast agent injection (Fig. 1). The lack of statistical significance after intravenous administration was in contrast with data reported previously by Judy et al. (2010) and can be explained by the small sample size used in this prospective pilot study. The deep digital flexor tendon did not show enhancement in normal condition, as described in other studies (Judy et al., 2010); in fact, tenoligamentous structures were poorly vascularized in absence of active lesions or angiogenic process.

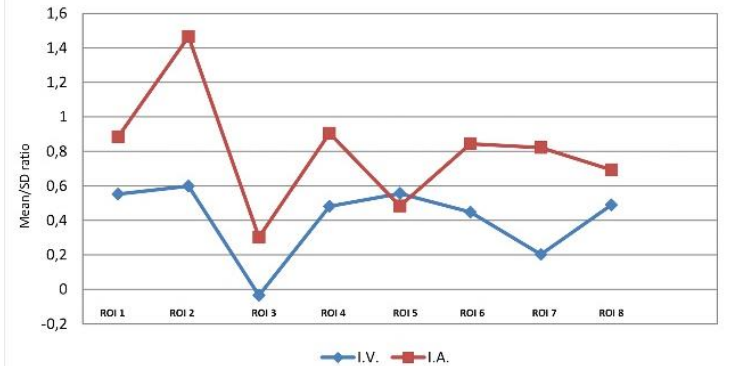

Fig. 1. The graphic shows the comparison between the mean ratios in the 8 ROI point after intravenous and intraarterial administration of contrast agent. The value of standard deviation (SD) are shown in brackets.

The high value of enhancement ratio observed at level of the dorsal cortical bone of the intermediate phalanx had to be considered as an artifact due to partial volume averaging (Pozzi Mucelli et al., 2008). A statistically significant difference between pre-contrast and postcontrast ROIs was noted when DDFT (Fig. 2 and Fig. 3 ) and DSIL were involved in pathological processes. The increase in value of post-contrast ROIs was more significant after intraarterial regional injection of contrast agent. In accordance with previously observed, it was possible to affirm that the use of contrast agent can implement the diagnostic capability of MRI in detection of tenoligamentous injuries. 


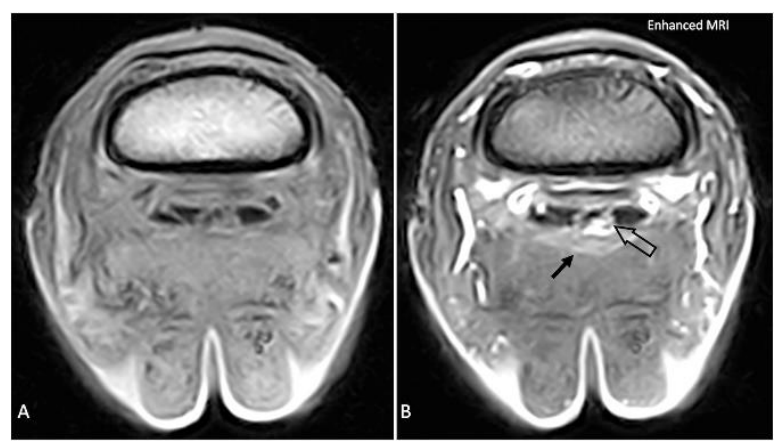

Fig. 2. Transverse pre- (A) and post-contrast after intraarterial regional administration (B) T1 weighted images (Point 7). In the pre-contrast image multiple DDFT parasagittal split lesions are visible in both tendon lobes. In the post-contrast image (B), note the enhancement of the tendon lesions (black open arrow) and of the palmar peritendinous tissues (black arrow).

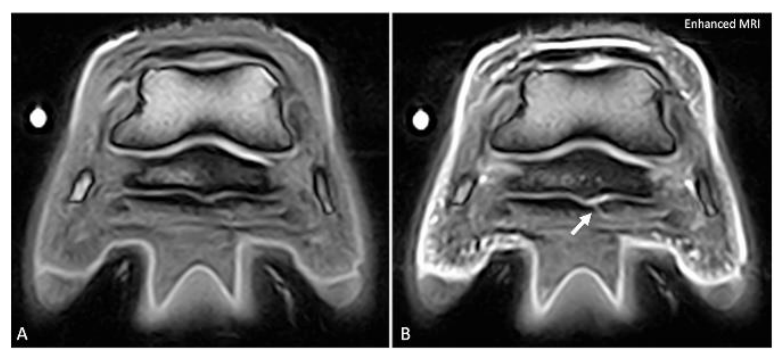

Fig. 3. Transverse pre- (A) and post-contrast after intravenous administration (B) T1 weighted images (Point 8). Enhanced image (B) shows an increase in signal in the navicular bone cortex and a parasagittal split of a DDFT lobe (white arrow).

The capability to enhance soft tissue injuries was strictly related to intrinsic characteristics of paramagnetic agent, as gadolinium, to selectively diffuse from vessels to extracellular/interstitial space. The diffusion from blood to extracellular/interstitial space became evident with the presence of injuries, due to an increase in capillary permeability, wall discontinuity of vascular endothelium, neonagiogenesis and granulation tissue formation (Movin et al., 1998; Puchalski et al., 2007; Severaid and Judy, 2012; Nelson et al., 2017). Otherwise, in absence of lesions and tissue damage, the contrast agent remained in the vessels without enhancement. As speculated by Judy et al. (2010), post-contrast sequences could allow to discriminate between active and chronic lesions (Nelson et al., 2017). In the present study, the presence of neoformed, fibrous-cicatricial enhancing tissue was observed in four horses. The intense tissue enhancement was considered suggestive of active lesions. During the healing process of a tenoligamentous structure, different phases characterized by changes in tissue vascularization and variation in the interstitial matrix can be observed (Movin et al., 1998; Shalabi et al., 2002; Shalabi, 2004; Sharma and Maffulli, 2005; Puchalsky et al., 2007;
Severaid and Judy, 2012). In the present study, a large number of DDFT lesions were noted. Usually, this type of lesion, characterized by an abnormal alignment and a cross linking of collagen fibers, appeares hyperintense on T1-weighted images, both in acute and chronic cases. Based on T1-weighted images, a correlation between the signal intensity of a lesion and a specific phase of the healing is not possible (Judy et al., 2008; Holowinsky et al., 2010; Vanel et al., 2012). In clinical practice, understanding of the DDFT lesions evolution is mandatory to obtain prognostic information and plan a proper rehabilitation program. Enhancement of a lesion after contrast agent administration could be an aid for discrimination between chronic injuries and lesions of clinical relevance. In some studies, authors (Holowinsky et al., 2010; Vanel et al., 2012) observed that resolution of tendon injuries on STIR was associated with improved lameness, suggesting that lesions visible on STIR images actively contribute to lameness.

Furthermore, lesions involving DSIL can be underestimated, especially using a low-field MRI (Judy et al., 2008). In our study, post-contrast sequences allowed visualization of DSIL injuries (two feet) and peritendinous soft tissue increased signal (Fig. 1) (4 feet), that were missed in non enhanced images. Some authors (Schramme et al., 2009; McGill et al., 2015) observed that saline bursography or saline arthrography of the distal interphalangeal joint can improve the visualization of the podotrochlear apparatus with lowfield MRI. Both techniques had some disadvantages; saline bursography prolongs duration of general anesthesia and increases the risk of bursa ruptures, while saline arthrography of the distal interphalangeal joint can be performed only in non-weight bearing horses and it is not feasible during standing MRI examination (McGill et al., 2015). On the other hand, gadolinium enhanced MRI can either be performed in standing patient and, in patient under general anesthesia, without a substantial increase of general anesthesia time.

In the present study two different ways of gadolinium administration have been used and compared, the intravenous (Judy et al., 2008; Severaid and Judy, 2012; De Zani et al., 2013) and the intraarterial injection. In veterinary medicine, intraarterial injection of contrast agent has been used with Computed Tomography (Puchalski et al., 2007, 2009; Carmalt and Montgomery, 2015), but there are no publications that describe the use of locoregional intraarterial contrast administration. Also in humans, intraarterial injection of gadolinium is also poorly discussed and its use is reported mainly in angiographic studies (Boos et al., 1998; Burry et al., 2004).

In our preliminary data, a more intense enhancement was observed after locoregional intraarterial contrast 
injection, in both pathologic and non-pathologic regions. The difference between contrast enhancement was statistically significant; nevertheless, further study with a large number of samples are mandatory. Indeed locoregional intraarterial injection allowed a major concentration of gadolinium by-passing the systemic circulation and directly reaching the region of interest.

Another advantage of regional intraarterial administration is the low dose of contrast agent required; the gadolinium dose usually reported for intravenous injection is $0.1-0.2 \mathrm{ml} / \mathrm{kg}$ body weight, while, in the present study we used for the intraarterial administration, a dose of $0.02 \mathrm{ml} / \mathrm{kg}$ body weight, dramatically reducing the total dosage and volume of contrast agent.

Even if the gadolinium-based contrast media have been associated with different types of toxicity, further studies are mandatory before drawing conclusion on the clinical implications of gadolinium accumulation in human and animal tissues (Ramalho et al., 2016; Pasquini et al., 2018). For these reasons, a potential toxicity must be seriously considered in all patients. On the basis of the published data, a reduction of the total dose must be achieved in order to decrease the risk of toxicity, especially in patients with renal impairment or renal failure (Ramalho et al., 2016). Furthermore, low dose of contrast agent can decrease the cost of contrast enhanced MR examination.

In the present study no adverse reactions or side effects have been observed in horses after contrast agent administration. In a previous study, Saveraid and Judy (2012) noted a mild and transient decrease in blood pressure after gadolinium injection when horses were in dorsal recumbency. In our study, no changes in blood pressure was observed, probably due to the different recumbency in which horses were positioned.

Arterial catheterization was performed at the level of the radial artery, without ultrasonographic guidance. The radial artery was chosen instead of the medial palmar artery because of its superficial localization that makes it easily digitally palpated (Puchalski et al., 2007; Spriet et al., 2015). In hind limb, the catheter was inserted into the dorsal metatarsal artery as for invasive blood pressure monitoring (Gent et al., 2015). In human medicine, ultrasound guidance for artery catheterization was preferred to traditional palpation because of higher first-attempt success rate and reduced incidence of hematoma (Tang et al., 2014). Nevertheless, in veterinary medicine there is no evidence to prefer one technique over another.

This was a clinical prospective pilot study and therefore the sample was small and unequal between the two groups. The small sample size precluded us from performing meaningful statistics. Another limitation is the lack of histology examination of the lesions and confirmation of the findings observed on MRI images.
In conclusion, contrast enhanced MRI should be considered as a useful tool for detection of tenoligamentous lesions in the equine patient that could provide information about staging of disease. On the basis of preliminary data, locoregional intraarterial administration via the radial artery is more valuable that intravenous injection due to its higher contrast enhancement using lower dose of gadolinium.

\section{Conflict of interest}

The authors declare that there is no conflict of interest.

\section{References}

Aarsvold, S., Solano, M. and Garcia-Lopez, J. 2018. Magnetic resonance imaging following regional limb perfusion of gadolinium contrast medium in 26 horses. Equine Vet. J. 50(5), 649-657.

Arat, A., Cekirge, H.S. and Saatci, I. 2000. Gadodiamide as an alternative contrast agent in cerebral angiography in a patient with sensitivity to iodinated contrast agent. Neuroradiology 42, 34-39.

Beltran, J., Chandnani, V., McGhee, R.A. Jr. and Kursunoglu-Brahme, S. 1991. Gadopentate dimeglumine-enhanced MR imaging of the musculoskeletal system. AJR Am. J. Roentgenol. 156, 457-466.

Boos, M., Lentschig, M., Scheffler, K., Bongartz, G.M. and Steinbrich, W. 1998. Contrast-enhanced magnetic resonance angiography of peropheral vessels. Different contrast agent applications and sequence strategies: a review. Invest. Radiol. 33, 538-546.

Burry, M.V., Cohen, J. and Mericle, R.A. 2004. Use of gadolinium as an intraarterial contrast agent for pediatric neuroendovascular procedures. J. Neurosurg. 100, 150-155.

Carmalt, J.L. and Montgomery, J. 2015. Intraarterial injection of iodinated contrast medium for contrast enhanced computed tomography of the equine head. Vet. Radiol. Ultrasound 56, 384-390.

De Zani, D., Zani, D.D., Binanti, D., Riccaboni, P., Rondena, M. and Di Giancamillo, M. 2013. Magnetic Resonance features of closed head trauma in two foals. Equine Vet. Educ. 25, 493-498.

Dyson, S. and Murray, R. 2007. Use of concurrent scintigraphic and magnetic resonance imaging evaluation to improve understanding of the pathogenesis of injury of the podotrochlear apparatus. Equine Vet. J. 39, 365-369.

Dyson, S., Pool, R., Blunden, T. and Murray, R. 2010. The distal sesamoidean impar ligament: comparison between its appearance on magnetic resonance imaging and histology of the axial third of the ligament. Equine Vet. J. 42, 332-339.

Eshed, I., Krabbe, S., Østergaard, M., Bøyesen, P., Møller, J.M., Therkildsen, F., Madsen, O.R., Axelsen, M. and Pedersen, S.J. 2015. Influence of 
field strength, coil type and image resolution on assessment of synovitis by unenhanced MRI-a comparison with contrast-enhanced MRI. Eur. Radiol. 25, 1059-1067.

Ferrell, E., Gavin, P., Tucker, R., Sellon, D. and Hines, M. 2002. Magnetic resonance for evaluation of neurologic disease in 12 horses. Vet. Radiol. Ultrasound 43, 510-516.

Gärdin, A., Brismar ,T.B., Movin, T. and Shalabi, A. 2013. Dynamic contrast enhanced magnetic resonance imaging in chronic Achilles tendinosis. BMC Med. Imaging 13, 39. Doi: 10.1186/14712342-13-39.

Gent, T.C, Schwarz, A., Hatz, L.A., Gozalo Marcilla, M., Schauvliege, S., Gasthuys, F. and BettschartWolfensberger, R. 2015. Evaluation of accuracy of invasive and non-invasive blood pressure monitoring in relation to carotid artery pressure in anaesthetised ponies. Pferdeheilkunde 31, 33-38.

Hodgson, R.J., O’Connor, P.J., Hensor, E.M., Barron, D. and Robinson, P. 2012. Contrast enhanced MRI of the subdeltoid, subacromial bursa in painful and painless rotator cuff tears. Br. J. Radiol. 85, 14821487.

Holowinsky, M., Judy, C.E., Severaid, T.C. and Maranda, L. 2010. Resolution of lesions on STIR images is associated with improved lameness status in horses. Vet. Radiol. Ultrasound 51, 479-484. Doi: https://doi.org/10.1111/j.17408261.2010.01692.x.

Judy, C.E., Saveraid, T.C., Rodgers, E.H., Rick, M.C. and Herthel, D.J. 2008. Characterization of Foot Lesions Using Contrast Enhanced Equine Orthopedic Magnetic Resonance Imaging. In: Proceedings. Am. Assoc. Equine Pract. 54, 459.

Judy, C.E., Saveraid, T.C., Rodgers, E., Rick, M.C. and Herthel, D. 2010. Contrast enhanced magnetic resonance imaging in the horse. Paper presented at: $15^{\text {th }}$ ESVOT congress. Proceedings of the $15^{\text {th }}$ ESVOT Congress, 15-18 September, Bologna, Italy.

McGill, S.L., Gutierrez-Nibeyro, S.D., Schaeffer, D.J., Hartman, S.K., O'Brien, R.T. and Joslyn, S.K. 2015. Saline arthrography of the distal interphalangeal joint for low-field magnetic resonance imaging of the podotrochlear bursa: feasibility study. Vet. Radiol. Ultrasound 56, 417424.

Movin, T., Kristoffersen-Wiberg, M., Shalabi, A., Gad, A., Aspelin, P. and Rolf, C. 1998. Intratendinous alterations as imaged by ultrasound and contrast medium-enhanced magnetic resonance in chronic achillodynia. Foot Ankle Int. 19, 311-317.

Murray, R.C., Dyson, S., Branch, M. and Schramme, M. 2007. Validation of magnetic resonance imaging use in equine limbs. Clin. Tech. Equine Pract. 6(1),
26-36.

Nelson, B.B., Goodrich, L.R., Barrett, M.F., Grinstaff, M.W. and Kawcak, C.E. 2017. Use of contrast media in computed tomography and magnetic resonance imaging in horses: techniques adverse events and opportunities. Equine Vet. J. 49, 410424.

Ntoulia, A., Papadopoulou, F., Zampeli, F., Ristanis, S., Argypropoulou, M. and Georgolius, A. 2013. Evaluation with contrast-enhanced magnetic resonance imaging of the anterior cruciate ligament graft during its healing process: a two year prospective study. Skeletal Radiol. 42, 541-552.

Pozzi Mucelli, R.S., Amezic, M. and Cova, M. 1998. Artefatti. In: Simonetti G, Del Maschio A, Bartolozzi C, Passariello R. Trattato italiano di Risonanza Magnetica. Napoli: Ed. IdelsonGnocchi, pp: 93-119.

Puchalski, S.M., Galuppo, L.D., Hornof, W.J. and Wisner, E.R. 2007. Intraarterial contrast enhanced computed tomography of the equine distal extremity. Vet. Radiol. Ultrasound 48, 21-29.

Puchalski, S.M., Galuppo, L.D., Drew, C.P. and Wisner, E.R. 2009. Use of contrast-enhanced computed tomography to assess angiogenesis in deep digital flexor tendinopathy in a horse. Vet. Radiol. Unltrasound 50, 292-297.

Puchalski, S.M. 2012. Advances in equine computed tomography and use of contrast media. Vet. Clin. North Am. Equine Pract. 28, 563-581.

Ramalho, J., Ramalho, M., Jay, M., Burke, L.M. and Semelka, R.C. 2016. Gadolinium toxicity and treatment. Magn. Reson. Imaging 34, 1394-1398.

Schmid, M., Hodler, J., Vienne, P., Binkert, C. and Zanetti, M. 2002. Bone marrow abnormalities of foot and ankle: STIR versus T1-weighted contrastenhanced fat-suppressed spin-echo MR imaging. Radiology 224, 463-469.

Schramme, M., Kerekes, Z., Hunter, S., Nagy, K. and Pease, A. 2009. Improved identification of the palmar fibrocartilage of the navicular bone with saline magnetic resonance bursography. Vet. Radiol. Ultrasound 50, 606-614.

Severaid, T.C. and Judy, C.E. 2012. Use of intravenous gadolinium contrast in equine magnetic resonance imagin. Vet. Clin. North Am. Equine Pract. 28, 617636.

Shalabi, A., Kristoffersen-Wiberg, M., Papadogiannakis, N., Aspelin, P. and Movin, T. 2002. Dynamic contrast-enhanced MR imaging and histopathology in chronic achilles tendinosis. Acta Radiol. 43, 198-206.

Shalabi, A. 2004. Magnetic resonance imaging in chronic Achilles tendinopathy. Acta Radiol. Suppl. 432, 1-45.

Sharma, P. and Maffulli, N. 2005. Tendon injury and 
tendinopathy: healing and repair. J. Bone Joint Surg. Am. 87, 187-202.

Sofka, C.M. and Potter, H.G. 2001. Magnetic resonance imaging of the wrist. Semin. Musculoskelet. Radiol. 5, 217-226.

Spinosa, D.J., Kaufmann, J.A. and Hartwell, G.D. 2002. Gadolinium chelates in angiography and interventional radiology: a useful alternative to iodinated contrast media for angiography. Radiology 223, 319-327.

Spriet, M., Trela, J.M. and Galuppo, L.D. 2015. Ultrasound-guided injection of the median artery in the standing sedated horse. Equine Vet. J. 47, 245248.

Tang, L., Wang, F., Li, Y., Zhao, L., Xi, H., Guo, Z., Li, X., Gao, C., Wang, J. and Zhou, L. 2014. Ultrasound Guidance for Radial Artery Catheterization: An Updated Meta-Analysis of Randomized Controlled Trials. PLoS ONE 9,11. Doi: 10.1371/journal.pone.0111527.

Tavares, W.C. Jr., de Castro, U.B., Paulino, E. J.r, Vasconcellos Lde, S., Madureira, A.P., Magalhães, M.A., Mendes, D.V., Kakehasi, A.M. and Resende, V. 2014. Healing of the Achilles tendon in rabbitsevaluation by magnetic resonance imaging and histopathology. J. Orthop. Surg. Res. 9, 132. Doi: 10.1186/s13018-014-0132-1.

Vallance, S.A., Bell, R.J., Spriet, M., Kass, P.H. and Puchalski, S.M. 2012. Comparisons of computed tomography, contrast-enhanced computed tomography and standing low-field magnetic resonance imaging in horses with lameness localised to the foot. Part 2: Lesion identification. Equine Vet. J. 44, 149-156.

Vanel, M., Olive, J., Gold, S., Mitchell, R.D. and Walker, L. 2012. Clinical significance and prognosis of deep digital flexor tendinopathy assessed over time using MRI. Vet. Radiol. Ultrasound 53, 621-627.

Van Hamel, S.E., Bergman, H.J., Puchalski, S.M., de Groot, M.W. and van Weeren, P.R. 2014. Contrastenhanced computed tomographic evaluation of the deep digital flexor tendon in the equine foot compared to macroscopic and histological findings in 23 limbs. Equine Vet. J. 46, 300-305.

Zeller, T., Müller, C., Frank, U., Bürgelin, K., Sinn, L., Horn, B., Flügel, P.C. and Roskamm, H. 2002. Gadodiamide as an alternative contrast agent during angioplasty in patients with contraindications to iodinated media. J. Endovasc. Ther. 9, 625-632. 